University of Nebraska - Lincoln

DigitalCommons@University of Nebraska - Lincoln

Resistance of Tripsacorn to Sitophilus zeamais and Oryzaephilus surinamensis

James E. Throne

USDA-ARS, Manhattan, KS, james.throne@ars.usda.gov

Mary W. Eubanks

Duke University

Follow this and additional works at: https://digitalcommons.unl.edu/usdaarsfacpub

Throne, James E. and Eubanks, Mary W., "Resistance of Tripsacorn to Sitophilus zeamais and Oryzaephilus surinamensis" (2002). Publications from USDA-ARS / UNL Faculty. 2063.

https://digitalcommons.unl.edu/usdaarsfacpub/2063

This Article is brought to you for free and open access by the U.S. Department of Agriculture: Agricultural Research Service, Lincoln, Nebraska at DigitalCommons@University of Nebraska - Lincoln. It has been accepted for inclusion in Publications from USDA-ARS / UNL Faculty by an authorized administrator of DigitalCommons@University of Nebraska - Lincoln. 


\title{
Resistance of Tripsacorn to Sitophilus zeamais and Oryzaephilus surinamensis
}

\author{
James E. Throne ${ }^{\mathrm{a}, *}$, Mary W. Eubanks ${ }^{\mathrm{b}}$ \\ ${ }^{a}$ US Department of Agriculture, Agricultural Research Service, Grain Marketing and Production Research Center, \\ 1515 College Avenue, Manhattan, KS 66502, USA \\ ${ }^{\mathrm{b}}$ Department of Biology, Duke University, Durham, NC 27708-0338, USA
}

Accepted 9 March 2001

\begin{abstract}
One strategy that has been used to find germplasm for developing improved plant varieties is to test ancestral germplasm for the desired traits. Although the progenitors of commercial maize are not known, a hybrid (called Tripsacorn) developed from a perennial teosinte, Zea diploperennis, and eastern gamagrass, Tripsacum dactyloides, resembles the earliest known samples of primitive domesticated maize. We tested resistance of whole Tripsacorn to the primary storage pest (primary storage pests can infest intact kernels) the maize weevil, Sitophilus zeamais Motschulsky (Coleoptera: Curculionidae), and resistance of ground Tripsacorn to the secondary storage pest (secondary pests usually cannot infest intact kernels) the sawtoothed grain beetle, Oryzaephilus surinamensis (L.) (Coleoptera: Silvanidae). Tripsacorn was immune to attack by $S$. zeamais. The weevils were unable to lay eggs in the Tripsacorn, and we hypothesized that the hardness of the fruitcase was responsible for lack of weevil oviposition. Oryzaephilus surinamensis were able to complete immature development on ground Tripsacorn, but duration of development was longer and weight of emerged adults was less than for beetles developing on wheat. Hardness of the fruitcase may have been a primitive mechanism of defense against insects and other pests, but probably would not be an acceptable trait in commercial varieties. It remains to be determined whether the possible antibiotic effect demonstrated in ground Tripsacorn would be a useful trait in commercial maize hybrids. (C) 2002 Elsevier Science Ltd. All rights reserved.
\end{abstract}

Keywords: Host plant resistance; Oryzaephilus surinamensis; Sitophilus zeamais; Tripsacum dactyloides; Tripsacorn; Zea diploperennis

\footnotetext{
*Corresponding author. Tel.: + 1-785-776-2796; fax: + 1-785-537-5584.

E-mail address: throne@usgmrl.ksu.edu (J.E. Throne).
} 


\section{Introduction}

Losses of stored grains due to insects and other storage problems are estimated to be greater than US\$ 1 billion annually in the United States (Cuperus and Krischik, 1995) and may exceed $30 \%$ in developing countries. Residual insecticides have been used routinely for many years to control insect pests in stored grain. However, use of residual insecticides is becoming less desirable because of development of resistance by insects to insecticides, regulatory restrictions on use of insecticides, and consumer desire for a pesticide-free product (Arthur, 1996). One alternative control technology that has been largely ignored since the widespread use of residual insecticides on stored grain is resistance of grains to insects. Most new grain varieties are selected for agronomic traits, such as yield, but not for resistance to pests in storage (Throne et al., 2000).

One strategy that has been used to find germplasm for developing improved plant varieties is to test ancestral germplasm (germplasm from progenitors of commercial varieties) for the desired traits. For example, Arnason et al. (1994) showed that some Mexican landraces of maize, Zea mays L., were resistant to maize weevils, Sitophilus zeamais Motschulsky (Coleoptera: Curculionidae), and that the resistance was correlated with phenolic acid content of the maize. There are many theories about the possible origin of maize (MacNeish and Eubanks, 2000), with hypothesized progenitors including an extinct wild maize and maize's closest extant wild relatives, teosinte and Tripsacum. A previously unknown wild relative of maize, Zea diploperennis Iltis, Doebley, and Guzmán, was discovered in the late 1970's in the mountains of Jalisco, Mexico (Iltis et al., 1979). Zea diploperennis is a perennial variety of teosinte. Eubanks (1992, 1995) was able to cross Zea diploperennis with eastern gamagrass, Tripsacum dactyloides (L.), supporting the hypothesis that Tripsacum could have played a role in the origin of maize. The hybrid closely resembles the earliest known samples of primitive domesticated maize (Eubanks, 1995). The cross with Tripsacum as the female parent is referred to as Tripsacorn (Eubanks, 1992). The kernels of Tripsacorn, like those of its parents, are enclosed in a hard, armor-like fruitcase [for a morphological description of the cupulate fruitcase, see Galinat (1970)]. The hybrid can be used as a genetic bridge for transferring Tripsacum genes into maize.

Given that Tripsacorn may be similar to the progenitors of modern maize and that Tripsacorn is resistant to corn rootworms (Eubanks, 1993), we initiated studies to determine whether Tripsacorn may have resistance to storage insect pests that could be incorporated into commercial maize hybrids. We tested resistance of intact Tripsacorn kernels to the maize weevil, a primary pest that can damage intact grain kernels. Based on results of that study, we also tested whether the sawtoothed grain beetle, Oryzaephilus surinamensis (L.) (Coleoptera: Silvanidae), a secondary pest that cannot damage intact grain kernels, could oviposit and complete development from egg to adult on ground Tripsacorn.

\section{Materials and methods}

\subsection{Resistance of whole kernels to maize weevils}

Tripsacorn was obtained from Sun Dance Genetics (Durham, NC). Asgrow RX899 maize used for our maize weevil culture was included as a control to ensure that the weevils used in the 
Tripsacorn study were capable of laying viable eggs that could develop to adults. Tripsacorn was cleaned over a US Standard No. 8 sieve $(2.38 \mathrm{~mm}$ openings), and the maize was cleaned over a US Standard No. 6 sieve ( $3.35 \mathrm{~mm}$ openings). We used different sizes of sieves because the Asgrow RX899 maize kernels are larger than the Tripsacorn kernels. We X-rayed (Throne, 1995) all kernels to ensure that they were not previously infested with insects. For X-raying, kernels were placed in a single layer on sheets of cellulose (previously exposed $13 \times 18 \mathrm{~cm}$ radiographs) that were coated with double-stick tape. A sheet of kernels was placed on a sheet of film (Kodak Industrex M X-ray film in Ready Pack II foil packs, Eastman Kodak, Rochester, NY) placed $56 \mathrm{~cm}$ below an X-ray source (Model 43855A Faxitron, Hewlett-Packard, McMinnville, OR) and exposed at $18 \mathrm{kV}$ and $3 \mathrm{~mA}$ for either 3 minutes for Tripsacorn or 4 minutes for maize. Negatives were examined under a stereomicroscope at a minimum of $12 \times$ magnification for the presence of any insect stage.

Kernels of maize or Tripsacorn $(35.0 \pm 0.1 \mathrm{~g})$ were placed in each of three plastic cages $(30 \mathrm{~mm}$ diam $\times 81 \mathrm{~mm}$ high) covered on the top with 100 -mesh brass screen. Cages were randomly placed in a plastic box $(28 \times 38.5 \times 15 \mathrm{~cm}$ high $)$ with a false floor over a saturated sodium chloride solution to maintain relative humidity within the box at $75 \%$ (Greenspan, 1977). An additional cage containing $300 \mathrm{~g}$ of the Asgrow maize was placed in the box to monitor moisture content weekly using a Motomco Model 919 automatic grain moisture tester (DICKEY-John, Auburn, IL). The samples were equilibrated for six weeks at $30^{\circ} \mathrm{C}$. These environmental conditions are nearly optimal for maize weevil population development (Throne, 1995) and were maintained throughout the study.

Maize weevils for the study were from a culture that originated with weevils collected in or around bins of maize in South Carolina in 1994 and were $F_{10-11}$ laboratory generation. The cultures were maintained on maize $\left(14-15 \%\right.$ moisture content) at $25^{\circ} \mathrm{C}$. Chilled weevils $(2-3-$ week-old) were sexed using snout characteristics (Tolpo and Morrison, 1965), and five females were placed in each cage for $72 \mathrm{~h}$ to oviposit. After the weevils were removed from cages, sex and identification of these females were confirmed by examination of genitalia after immersion of weevils in ethanol (Whitehead, 1991). Samples were sieved daily, starting 13 days after ovipositing females were removed and continuing until no weevils had emerged in each cage for 2 weeks. Samples were again X-rayed after emergence was complete to determine whether there were dead insects in kernels.

\subsection{Resistance of ground kernels to sawtoothed grain beetles}

Because weevils did not oviposit in Tripsacorn in the first study, we conducted a second study to determine whether ground Tripsacorn could support insect development. We used $O$. surinamensis in the study, rather than maize weevils, because $O$. surinamensis readily complete development in ground grain whereas maize weevils do not (Meagher et al., 1982). We used hard red winter wheat (Triticum aestivum L.) of unknown variety as a control to ensure that the beetles used in the study were capable of laying viable eggs that could develop to adults. We used wheat as a control, rather than maize, because we wanted to provide each insect with an entire kernel to ensure that all parts of the kernel were available for oviposition and feeding. Tripsacorn kernels are small and closer in weight to wheat than maize. We would have needed many more Tripsacorn kernels if we had used one maize kernel and a comparable weight of Tripsacorn kernels for each 
replication, and we had a limited supply of Tripsacorn kernels. Development of a related species, the merchant grain beetle [O. mercator (Fauvel)], is similar on maize and wheat (LeCato, 1974). We selected 20 Tripsacorn kernels and 20 pairs of wheat kernels that weighed between 58 and $70 \mathrm{mg}$ (i.e., a Tripsacorn kernel weighs twice as much as a wheat kernel, so we used two wheat kernels to approximate the weight of one Tripsacorn kernel). Kernels were individually ground (pairs for wheat) with a mortar and pestle, and the resulting material was placed in a $0.5 \mathrm{ml}$ microcentrifuge tube with a pinhole in the lid. Tubes, with the lids open, were randomly placed in a plastic box over sodium chloride at $30^{\circ} \mathrm{C}$ to equilibrate for 3 weeks. These environmental conditions are nearly optimal for population development of sawtoothed grain beetles (Howe, 1956) and were maintained throughout the study.

Several hundred unsexed sawtoothed grain beetles, from a colony that has been maintained at the Grain Marketing and Production Research Center for many years on rolled oats containing small amounts of wheat germ and brewers' yeast and reared at $25^{\circ} \mathrm{C}$ and $60-65 \%$ r.h., were placed in a pint (ca. $473 \mathrm{ml}$ ) jar containing wheat flour and allowed to oviposit for 24 hours. Eggs were sieved from the flour over US Standard No. 70 and 30 sieves (212 and $600 \mu \mathrm{m}$ openings, respectively). A single egg was placed in each microcentrifuge tube using a fine brush. Starting 15 days after eggs were placed in tubes, tubes were examined every 3.5 days (without disturbing the contents) for an adult.

We noticed that progeny reared on Tripsacorn appeared to be smaller than those reared on wheat, so we conducted an additional test in which emerged adults were chilled in a refrigerator (ca. $3^{\circ} \mathrm{C}$ ) shortly after emergence and then weighed. Methods were modified slightly from those used in the previous study by increasing the number of Tripsacorn kernels or pairs of wheat kernels to 30 ; collecting eggs for $24 \mathrm{~h}$ at $30^{\circ} \mathrm{C}$; and starting to check tubes daily for emerged adults 17 days after eggs were placed in tubes.

\section{Results}

\subsection{Resistance of whole kernels to maize weevils}

No weevils were produced on the Tripsacorn, and X-ray examination of the kernels indicated that no eggs had been laid in the kernels. Mean $( \pm$ SEM) progeny production on the Asgrow maize was $30.3 \pm 3.7(n=3)$, which was significantly different from $0(t=8.2, P=0.01)$, demonstrating that weevils used in the study were capable of laying viable eggs that could develop to adults. Moisture content of the 300-g sample of Asgrow maize ranged from 14.1 to $14.7 \%$, wet weight, during the study $(\bar{x} \pm \mathrm{SEM}=14.4 \pm 0.05 \%)$.

\subsection{Resistance of ground kernels to sawtoothed grain beetles}

O. surinamensis were able to oviposit and complete development from egg to adult on ground Tripsacorn. Survivorship on Tripsacorn was similar to that on wheat-11 and 12 (of 20) adults emerged on wheat and Tripsacorn, respectively, in the first test, and 14 and 16 (of 30) adults emerged on wheat and Tripsacorn, respectively, in the second test. Duration of development on 


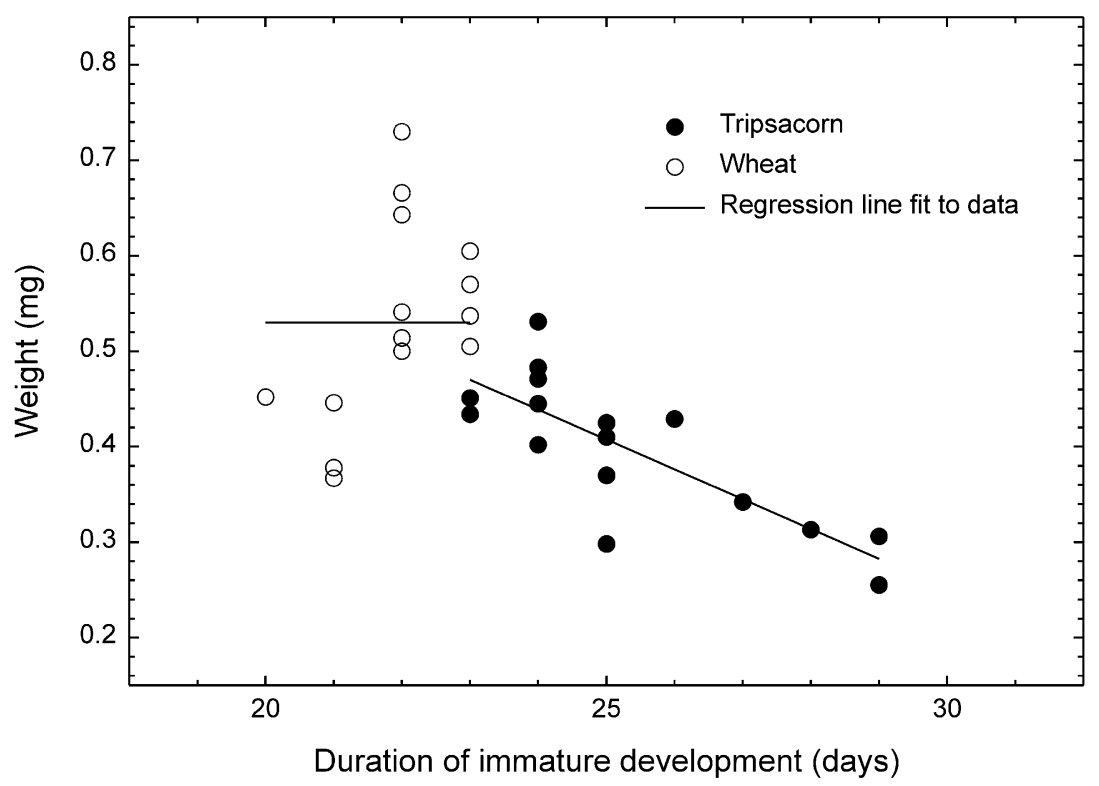

Fig. 1. Relationship between adult weight and duration of immature development of sawtoothed grain beetles that developed from eggs placed in ground wheat or Tripsacorn. Wheat: weight $(\mathrm{mg})=0.53( \pm 0.03)$. Tripsacorn: weight $(\mathrm{mg})=1.19( \pm 0.16)-[0.0313( \pm 0.0063) \times$ days $]$. Numbers in parentheses are standard errors of the equation parameters.

Tripsacorn was similar to that on wheat in the first test $(\bar{x} \pm \mathrm{SEM}=24.5 \pm 0.0$ days vs. $24.5 \pm 0.5$ days, respectively). However, when adults were removed daily in the second test (rather than every 3.5 days in the first test), duration of development was longer on Tripsacorn than on wheat $(25.3 \pm 0.5$ vs. $21.9 \pm 0.2$ days, respectively; $F=35.0 ; \mathrm{df}=1,29 ; P<0.01)$. Weight of emerged adults on Tripsacorn was less than on wheat $(0.40 \pm 0.02 \mathrm{mg}$ vs. $0.53 \pm 0.03 \mathrm{mg}$, respectively; $F=16.4 ; \mathrm{df}=1,29 ; P<0.01)$. Beetles emerging first on Tripsacorn weighed more than those that emerged later (Fig. $1 ; r=-0.80, P[r>0]<0.01$ ). Weight and emergence time were not correlated on wheat $(r=0.52, P[r>0]=0.055)$.

\section{Discussion}

Whole Tripsacorn kernels were immune to attack by maize weevils. The Tripsacorn kernels were difficult to grind because of the hardness of the fruitcase, and weevils probably were unable to lay eggs in the Tripsacorn because of the hardness of the fruitcase. It is also possible that there is a repellent in the fruitcase that deters oviposition. Protection of the fruit by the fruitcase may have been a primitive method of defense against insects and other pests. When protection of the fruit by the fruitcase was compromised by grinding, O. surinamensis were able to oviposit and complete development from egg to adult on Tripsacorn. This does not support the hypothesis that there may be a repellent in the fruitcase, unless the repellent is inactivated by grinding. It seems more likely that the hardness of the fruitcase protects the fruit. Thus, Tripsacorn is not immune to 
insect attack once the fruitcase is compromised. Primary pests that are strong borers, such as the larger grain borer [Prostephanus truncatus (Horn)] or the lesser grain borer [Rhyzopertha dominica (F.)], may be able to damage intact Tripsacorn kernels. However, secondary pests would be unlikely to damage intact Tripsacorn kernels.

Another feature of grain morphology that provides a protective barrier is the pericarp that surrounds the fruit. Pericarp hardness has been associated with resistance to maize weevils (e.g., Classen et al., 1990). Pericarp morphology probably does not contribute to resistance in Tripsacorn because the thickness and number of cell layers in the pericarp is significantly less in the wild relatives than it is in maize (Tracy and Galinat, 1987). In Tripsacum and teosinte, pericarp thickness ranges from 25 to $30 \mu \mathrm{m}$ and there are only two to three cell layers; whereas in maize, pericarp thickness ranges from 57 to $182 \mu \mathrm{m}$ and numbers of cell layers range from 5 to 21. There is little evolutionary impetus for the development of a hard pericarp in Tripsacum and teosinte to protect from insect attack if their fruitcases provide immunity to insect attack, as in Tripsacorn.

Weight of $O$. surinamensis progeny developing on ground Tripsacorn was lower than for those developing on ground wheat. [Although we did not test development of $O$. surinamensis on ground maize, weights of $O$. mercator progeny developing on maize and wheat are similar (LeCato, 1974).] This suggests that Tripsacorn kernels may impair insect development, and thus may have an inherited property that could provide protection from insects capable of penetrating the hard fruitcase. Evidence of antibiosis (higher mortality and reduced larval size) in Tripsacorn has been shown with corn rootworms (Eubanks, 1994, 1998). While we do not know the mechanism of antibiotic resistance in Tripsacorn, one possible chemical defense response in grain is production of proteinase inhibitors with insecticidal activity (Reeck et al., 1997). Although there was no apparent correlation between proteinase inhibition and rootworm resistance in Tripsacorn (Eubanks and Cook, 2000), there was a wide range of inhibitory activity in individual maize $\times$ Tripsacorn plants for every line tested. Therefore, if there is antibiotic resistance in Tripsacorn, it should be possible to select plants with high levels of antibiotic activity and transfer the trait from Tripsacorn to maize in a recurrent selection breeding program.

The commercial potential of Tripsacorn or of hybrids produced from Tripsacorn for food and/ or feed use has not been determined. However, the hardness of the fruitcase will have to be bred out in the development of commercial varieties and this probably will eliminate the immunity demonstrated to maize weevils. Thus, this probably is not a useful trait for development of new maize hybrids with resistance to storage insect pests. But, if Tripsacorn can impart an antibiotic effect, this may be important for the production of maize seed with resistance to insects that cause significant grain losses during storage. Further selection may result in Tripsacorn hybrids with antibiotic resistance to storage insect pests.

\section{Acknowledgements}

We thank Ann Redmon for technical assistance; and Walton C. Galinat, Robert L. Meagher, Jr., and Megha N. Parajulee for reviewing an earlier version of the manuscript. M. Eubanks gratefully acknowledges support under National Science Foundation grants 9660146, 9801386, and DEB-94-15541. 


\section{References}

Arnason, J.T., Baum, B., Gale, J., Lambert, J.D.H., Bergvinson, D., Philogene, B.J.R., Serratos, J.A., Mihm, J., Jewell, D.C., 1994. Variation in resistance of Mexican landraces of maize to maize weevil Sitophilus zeamais, in relation to taxonomic and biochemical parameters. Euphytica 74, 227-236.

Arthur, F.H., 1996. Grain protectants: current status and prospects for the future. Journal of Stored Products Research 32, 293-302.

Classen, D., Arnason, J.T., Serratos, J.A., Lambert, J.D.H., Nozzolillo, C., Philogène, B.J.R., 1990. Correlation of phenolic acid content of maize to resistance to Sitophilus zeamais, the maize weevil, in CIMMYT's collections. Journal of Chemical Ecology 16, 301-315.

Cuperus, G., Krischik, V., 1995. Why stored product integrated pest management is needed. In: Krischik, V., Cuperus, G., Galliart, D. (Eds.), Stored Product Management. Oklahoma State University Cooperative Extension Service Circular E-912, Oklahoma Cooperative Extension Service, Stillwater, OK, p. 199.

Eubanks, M.W., 1992. Corn plant named Tripsacorn. United States Patent PP7,977.

Eubanks, M., 1993. Corn rootworm resistance conferred to maize via Tripsacum $\times$ Zea diploperennis. Maize Genetics Cooperation Newsletter 67, 39-41.

Eubanks, M.W., 1994. Methods and materials for conferring Tripsacum genes in maize. United States Patent 5,330,547.

Eubanks, M., 1995. A cross between two maize relatives: Tripsacum dactyloides and Zea diploperennis (Poaceae). Economic Botany 49, 172-182.

Eubanks, M.W., 1998. Methods and materials for conferring Tripsacum genes in maize. United States Patent 5,750,828.

Eubanks, M.W., Cook, C., 2000. Assay for proteinase inhibition in Tripsacum-Zea diploperennis $\times$ maize hybrids resistant to western corn rootworm. Maize Genetics Cooperation Newsletter 74, 30-31.

Galinat, W.C., 1970. The cupule and its role in the origin and evolution of maize. University of Massachusetts Agricultural Experiment Station Bulletin 585.

Greenspan, L., 1977. Humidity fixed points of binary saturated aqueous solutions. Journal of Research of the National Bureau of Standards 81A, 89-96.

Howe, R.W., 1956. The biology of the two common storage species of Oryzaephilus (Coleoptera, Cucujidae). Annals of Applied Biology 44, 341-355.

Iltis, H.H., Doebley, J.F., Guzmán, R., Pazy, B., 1979. Zea diploperennis (Graminae): a new teosinte from Mexico. Science 203, 186-188.

LeCato, G.L., 1974. Population growth and body weight of merchant grain beetles reared on cereals or peanuts supplemented with eggs or adults of the Indian meal moth. Journal of the Georgia Entomological Society 9 , 198-203.

MacNeish, R.S., Eubanks, M.W., 2000. Comparative analysis of the Río Balsas and Tehuacán models for the origin of maize. Latin American Antiquity 11, 3-20.

Meagher Jr., R.L., Reed, C., Mills, R.B., 1982. Development of Sitophilus zeamais and Tribolium castaneum in whole, cracked, and ground pearl millet. Journal of the Kansas Entomological Society 55, 91-94.

Reeck, G.R., Kramer, K.J., Baker, J.E., Kanost, M.R., Fabrick, J.A., Behnke, C.A., 1997. Proteinase inhibitors and resistance of transgenic plants to insects. In: Carozzi, N., Koziel, M. (Eds.), Advances in Insect Control: The Role of Transgenic Plants. Taylor and Francis, Ltd., London, UK, pp. 157-183.

Throne, J.E., 1995. Life history of immature maize weevils (Coleoptera: Curculionidae) on corn stored at constant temperatures and relative humidities in the laboratory. Environmental Entomology 23, 1459-1471.

Throne, J.E., Baker, J.E., Messina, F.J., Kramer, K.J., Howard, J.A., 2000. Varietal resistance. In: Subramanyam, Bh., Hagstrum, D.W. (Eds.), Alternatives to Pesticides in Stored-Product IPM. Kluwer Academic Publishers, Norwell, MA, pp. 165-192.

Tolpo, N.C., Morrison, E.O., 1965. Sex determination by snout characteristics of Sitophilus zeamais Motschulsky. Texas Journal of Science 17, 122-124.

Tracy, W.F., Galinat, W.C., 1987. Thickness and cell layer number of the pericarp of sweet corn and some of its relatives. HortScience 22, 645-647.

Whitehead, D.R., 1991. Weevils (Curculionidae, Coleoptera). In: Gorham, J.R. (Ed.), Insect and Mite Pests in Food, An Illustrated Key. USDA, ARS Agriculture Handbook 655, Vol. 1, pp. 223-230. 